\title{
It Must be True - But How Can it Be? Some Remarks on Panpsychism and Mental Composition
}

\author{
PIERFRANCESCO BASILE
}

\begin{abstract}
Although panpsychism has had a very long history, one that goes back to the very origin of western philosophy, its force has only recently been appreciated by analytic philosophers of mind. And even if many still reject the theory as utterly absurd, others have argued that it is the only genuine form of physicalism. This paper examines the case for panpsychism and argues that there are at least good prima facie reasons for taking it seriously. In a second step, the paper discusses the main difficulty the theory has to face, the 'composition problem'. This is the problem of explaining how the primitive experiences that are supposed to exist at the ultimate level of reality could give rise to the unified experience of a human being. What assumptions as to the nature of experience generate the composition problem? Is mental composition impossible in principle or do we simply lack at present any understanding of phenomenal parts and wholes?
\end{abstract}

\section{Introduction}

Analytical philosophy of mind has recently witnessed a revival of interest in the old-fashioned doctrine of panpsychism - the view that experience is a pervasive feature of reality. The doctrine is not uncontroversial; while some embrace it almost enthusiastically, others reject it as outrageously absurd. On the one hand, there are supporters like David Skrbina, who argues that 'panpsychism... offers resolutions to mind-body problems that dualism and materialism find intractable'. ${ }^{1}$ On the other end of the scale, one finds pitiless critics like Colin McGinn, who compares panpsychism unfavourably with Cartesian dualism and belief in divine providence, arguing that the theory is not even a form of supernaturalism - it is 'merely extravagant'. ${ }^{2}$

As it will be argued, the right attitude should be neither one of condemnation nor one of uncritical endorsement. There are wholly

1 D. Skrbina, Panpsychism in the West (Cambridge, Mass.: The MIT Press, 2005), 4; my emphasis.

2 C. McGinn, The Problem of Consciousness: Essays Towards a Resolution (Oxford: Blackwell, 1991), 2n. 


\section{Pierfrancesco Basile}

cogent lines of reasoning conducive to it; at the same time, its viability is threatened by a few as yet unanswered questions. To put it in a way more favourable to the panpsychist: the doctrine cannot be taken to provide a fully satisfactory explanation of the place of consciousness in nature; it does have its own strengths, however, and does therefore deserve a fair hearing.

\section{Physics, Metaphysics, Commonsense}

John Searle provides a brief criticism of panpsychism in his book of 2004, Mind: A Brief Introduction. His assessment is as good a point of departure for an evaluation as one could possibly wish. The present paper can be read as a response to what he says there:

Panpsychism is the view that consciousness is everywhere. This view is seldom stated explicitly, but it is in several authors particularly among the mysterians who think that if we are going to explain consciousness in terms of microprocesses, then, somehow or other, some form of consciousness must already be present in the microprocesses.... On this view, everything is conscious to some degree. In giving an example of the ubiquity of consciousness, Chalmers eloquently describes what it might be like to be a conscious thermostat. ${ }^{3}$

After this brief - and hardly sympathetic - characterization of the theory, Searle launches his attack:

Aside from its inherent implausibility, panpsychism has the additional demerit of being incoherent. I do not see any way that it can cope with the problem of the unity of consciousness. ... If the thermostat is conscious, how about the parts of the thermostat? Is there a separate consciousness to each screw? Each molecule? If so, how does their consciousness relate to the consciousness of the whole thermostat? And if not, what is the principle that makes the thermostat the unit of consciousness and not the parts of the thermostat or the whole heating system of which the thermostat is a part or the building in which the heating system exists? ${ }^{4}$

3 J. Searle, Mind: A Brief Introduction (Oxford-New York: Oxford University Press, 2004), 149-50.

$4 \quad$ Ibid., 150. 
This passage nicely summarizes what can be said - and what has in fact been said - against panpsychism; one will have to disentangle, however, Searle's misunderstandings from his genuine insights. Let's begin with what is most obviously unsatisfactory, namely his rejection of panpsychism on the ground of its 'inherent implausibility'.

Charges of implausibility are notoriously hard to evaluate - by what standards is the plausibility of a philosophical theory to be tested? Searle does not say. The standard can hardly be commonsense; if it were, this would suffice to reject all the -isms in the philosophy of mind (perhaps, only such a vituperated doctrine as Cartesian dualism would avoid such a wholesale condemnation!). Be that as it may, it is difficult to see why panpsychism should be regarded as more absurd than any of the existing forms of materialism, which enjoy on the contrary a very wide acceptance.

Is it 'science', then, that provides the required standard? The problem here is that it is unclear what this is supposed to mean. Should one include, say, physics, chemistry, biology, or only one of these? And why exactly is science supposed to rule out panpsychism? Appeals to 'our best scientific theories' are common in the philosophy of mind, yet quite often they are little more than empty slogans: I suspect that there is more than a grain of truth in Ross and Ladyman's critique of recent works in analytic philosophy of mind as being based upon a 'pseudo-scientific metaphysics'.$^{5}$

Most importantly, panpsychists argue that natural science does not make any positive claim about the intrinsic nature of reality; rather, they claim that science limits itself to the study of the formal properties of the investigated objects. As Russell says with regard to our knowledge of matter:

[I]t is only mathematical properties that we can discover... The physical world is only known as regards certain abstract features of its space-time structure - features which, because of their abstractness, do not suffice to show whether the physical world is, or is not, different in its intrinsic character from the world of mind. ${ }^{6}$

5 D. Ross and J. Ladyman (with D. Spurrett and J. Collier), Every Thing Must Go: Metaphysics Naturalized (Oxford: Oxford University Press, 2007), 18-27.

6 B. Russell, Human Knowledge: Its Scope and Limits (London: Routledge, 1948), 240. 


\section{Pierfrancesco Basile}

Thus, so the argument goes, there cannot possibly be anything in science that contradicts panpsychism: 'physics' and 'meta-physics' operate at distinct explanatory levels. True, the notion that science has nothing to say about the ultimate nature of things is not an obvious one, but the argument needs to be addressed in its own terms - a generic appeal to implausibility will not suffice.

Another noteworthy feature of the passage is Searle's contention that panpsychism is 'seldom stated explicitly'. Doesn't this suggest that panpsychists are a little dishonest, afraid, as it were, to clearly come into the fore? This can't be right; the list of philosophers explicitly committed to some form of panpsychism is not as brief as Searle would make us believe. The doctrine has an impressive history, one which includes names as venerable as those of Gottfried Wilhelm Leibniz, Benedict de Spinoza, Charles Sanders Peirce, William James, and Alfred North Whitehead. In recent times, the likes of philosophers such as David Chalmers, William Seager and Thomas Nagel have argued that it is a hypothesis worth contemplating. And it has been forcefully advocated by Charles Hartshorne, David Ray Griffin, David Skrbina, Galen Strawson, and Timothy Sprigge.

Ipse dixit? This is not, of course, an appeal to authority; nor is it simply a pedantic attempt at setting the record straight. The point is that panpsychism is not to be viewed as an historical anomaly; it should not, therefore, be dismissed as a philosophical eccentricity.

\section{The Ubiquity of Experience}

This might not be enough to dispel the suspicion that the theory is implausible - if not even obviously absurd. Searle touches upon a serious problem at the very end of the quoted passage. What he has in mind is the specific version of panpsychism that has been tentatively advocated by David Chalmers in The Conscious Mind. On this version of the theory, a thermostat has a claim to be regarded as sentient. But a thermostat is made up of parts (the screws, the molecules), and is itself part of larger complexes (the whole heating system, the building). Quite rightly, Searle asks why only the thermostat should be regarded as sentient. Where - and, most importantly, how - do we draw the line between the sentient and the non-sentient?

In the case of Chalmers' version of panpsychism, the answer is straightforward. Since he speculates that experience might be linked with information, whatever can be regarded as an information 
system could also be regarded as endowed with experiences. ${ }^{7}$ The real issue here is to account for the nature of the link that connects information and experience; nothing is truly explained by arguing that experience and information are like the two sides of a manuscript recto and verso.

In general, two lines of response are available to the panpsychist. (1) One is to ascribe experiences to everything that exists. In a recent essay, David Skrbina argues that there is no difference in kind between a human being and a rock ('the rock experiences the world, and we experience the world'), before going on to ascribe a mental life to 'all things that exist - from atoms and rocks, to tables and chairs, to human beings, planets, and stars'. This is legitimate, but it isn't very satisfying; it simply doesn't ring true that the theory 'finds justification in... empiricism'. 8 There is nothing in our experience that even slightly suggests that sticks and stones, tables and chairs, planets and galaxies, are experiencing things. As John Dewey recognized, ' $[\mathrm{t}]$ here is no evidence that experience occurs everywhere and everywhen'. ${ }^{9}$ On the contrary, at least in some cases, our experience suggests (although it does not prove) the opposite view. Stones are incapable of spontaneous movement and reaction, which clearly demarcates them from those organisms such as human and non-human animals - to which we do not hesitate to ascribe a conscious, experiential life. Although empirical observation does not show that sentience is not ubiquitous, we should treat its deliverances as we are supposed to treat a literary text that is to say, we should not read too much into them.

This critique differs radically from Wittgenstein's remark in the Philosophical Investigations: 'Could one imagine a stone's having consciousness? And if anyone can do so - why should that not merely prove that such image-mongery is of no interest to us?" 10 The point is not that a panpsychism that goes so far as to ascribe mental states to such things as sticks and stones would be meaningless; we can make some sense of such a proposal. Simply, such a version of

7 D. Chalmers, The Conscious Mind (Oxford-New York: Oxford University Press, 1996), 293.

8 D. Skrbina, 'Transcending Consciousness: Thoughts on a Universal Conception of Mind', Fournal of Consciousness Studies 16:5 (2009), 81 and 84 .

J. Dewey, Experience and Nature (New York: Dover, 1958), 3a.

10 L. Wittgenstein, Philosophical Investigations, edited by G. E. M. Anscombe and R. Rhees (Oxford: Blackwell, 1953), §390. 


\section{Pierfrancesco Basile}

panpsychism would assume more than is empirically warranted ${ }^{11}$ and, arguably, more than is needed for explanatory purposes.

(2) This becomes clearer if one considers the other option which remains open to the panpsychist. Specifically, it is possible to differentiate between wholes which, considered as such, are capable of sentience from wholes which, considered as such, are deprived of experience. The panpsychist might then choose to qualify the notion that experience is ubiquitous by making the following proposal (with ' $\mathrm{E}$ ' and 'NE' standing for 'experiential' and 'non-experiential' respectively):

[A] All ultimate constituents of reality are sentient.

[B] When such ultimates are grouped in certain special ways say, the $E$-ways - they give rise to complexes that are themselves sentient.

[C] When they are grouped in different ways - say, the $N E$-ways they give rise to complexes that are themselves insentient.

This would not be implausible. There is no reason to believe that a complex must be sentient solely because its parts are; this would be an instance of the fallacy of composition. Conversely, there is no reason to believe that there is no experience in the parts, solely because the whole is not itself an experiencing thing; this would be an instance of the fallacy of division. There is nothing that suggests permanence and immovability more vividly than a solid piece of rock, yet we have no difficulty in accepting the scientific description of it as composed of vibrating, energizing particles. It is at least conceivable that the same could be true of the sentient/insentient distinction.

In order to be entitled to hold a position of this sort, however, the panpsychist must be able to explain what 'principle' accounts for the fact that only certain wholes posses a unified consciousness. One would need a clear account of the distinction between those ways of organization that give rise to sentient wholes (the $E$-ways) and

11 One truly major thinker who went so far as to ascribe experiences to all things is Spinoza. It is significant that this claim was not established empirically, but was inferred as a corollary of a general metaphysical theory established on a priori grounds. Specifically, given his substance metaphysics and the parallelism that goes with it, every mode of extension has its counterpart in a mode of thought. Thus, there must be of necessity a mental correlate to each physical thing. His metaphysical principles, he argues, 'are completely general and do not pertain more to man than to other individuals, all of which, though in different degrees, are nevertheless animate'. B. Spinoza, Ethics, edited and translated by E. Curley (London: Penguin Books, 1994), 2p13. 
those that do not (the $N E$-ways). Such a theory would be less difficult to digest, but it would be a hard task to work it out. A speculative philosopher such as Whitehead appears at times to be proposing a tremendously intricate taxonomy of complex individuals, although only in a sketchy manner. ${ }^{12}$ To the best of my knowledge, the detailed articulation of such a theory has yet to be provided.

\section{The Heterogeneity Problem}

The above considerations show that the panpsychist need not be committed to the view that apparently inert objects such as rocks or thermostats have experiences. In order to dispel fully the suspicion that the theory is absurd, however, one has to consider the reasons in its support. Searle condemns the view as a form of 'mysterianism' but doesn't make the slightest effort to explain why very intelligent philosophers should have come to entertain such an apparently strange idea in the first place.

Although a variety of arguments has been advanced over the centuries, the one that is likely to get a hearing in the current philosophical climate pivots upon the notion of emergence. James provides a vivid illustration of the perplexity that grounds the panpsychist's case in his Principles of Psychology:

The point which as evolutionists we are bound to hold fast to is that all the new forms of being that make their appearance are really nothing more than results of the redistribution of the original and unchanging materials. The self-same atoms which, chaotically dispersed, made the nebula, now, jammed and temporarily caught in peculiar positions, form our brains; and the 'evolution' of the brains, if understood, would be simply the account of how the atoms came to be so caught and jammed. In this story no new natures, no factors not present at the beginning, are introduced at any later stage.

But with the dawn of consciousness an entirely new nature seems to slip in, something whereof the potency was not given in the mere outward atoms of the original chaos. ${ }^{13}$

12 A. N. Whitehead, Process and Reality: An Essay in Cosmology, corrected edition by D. R. Griffin and D. W. Sherburne (New York: The Free Press, 1978), 83-109.

13 W. James, The Principles of Psychology, Vol. I. (New York: Dover, 1950), 146. 


\section{Pierfrancesco Basile}

The obvious conclusion is that in an evolutionary universe experience must be present from the very beginning. One of Russell's teachers at Cambridge, James Ward, argued as follows:

It is interesting... to notice that in the support which it lends to pampsychist views the theory of evolution seems likely to have an effect on science the precise opposite of that which it exercised at first. That was a leveling down, this will be a leveling up. At first it appeared as if man were only to be linked with the ape, now it would seem that the atom, if reality at all, may be linked with man. ${ }^{14}$

This is a truly remarkable passage and its power should not pass unnoticed. Even today - and not solely in the popular press - evolution is associated with a materialistic conception of reality; in orthodox circles, it is even rejected on this very ground. If Ward is right, however, then the link between evolution and materialism might not be as close as we are accustomed to think. The theory of evolution need not necessarily degrade consciousness, for it might spiritualize matter.

In remarking that the generation of the experiential from the nonexperiential would involve a break of evolutionary continuity, James and Ward are raising the 'heterogeneity problem'. This is a difficulty Galen Strawson has recently stated in very clear terms. ${ }^{15}$ As he puts it, the problem arises for a philosopher inclined to hold the following two theses (with 'NE' and 'RE' standing for 'non-experiential' and 'real physicalism' respectively):

$[\mathrm{NE}]$ physical stuff is, in itself, in its fundamental nature, something wholly and utterly non-experiential.

[RP] experience is a real concrete phenomenon and every real concrete phenomenon is physical.

The problem here is to reconcile the belief that mental phenomena are physical, $[\mathrm{RP}]$, with our deep ingrained intuition that physical stuff

14 J. Ward, 'Mechanism and Morals: The World of Science and the World of History' in Essays in Philosophy: with a Memoir by Olwen Ward Campell, edited by W. R. Sorley and G. F. Stout (Cambridge: Cambridge University Press, 1927), 247.

15 G. Strawson, 'Real Materialism: Why Physicalism Entails Panpsychism' in Consciousness and its Place in Nature: Does Physicalism Entail Panpsychism?, edited by A. Freeman (Exeter: Imprint Academic, 2006), 12-21. 
isn't experiential, [NE]. Most philosophers would surely wish to believe both. Yet it is not easy to see how they could be entitled to do so, for if $[\mathrm{RP}]$ is true, then some real things are both physical and experiential, which is what $[\mathrm{NE}]$ denies.

The way out of this impasse is supposed to be provided by the notion of emergence. When purely physical stuff achieves a certain degree of complexity in its organization, then new properties experiential properties - come into existence. In this way, it becomes possible to hold that all physical stuff is, in its fundamental nature, non-experiential $[\mathrm{NE}]$, without having to deny that experiential phenomena are wholly physical $[\mathrm{RP}]$, since they are now conceived as the outcome of wholly natural processes. In a book entitled Mind and Emergence, for example, Philip Clayton characterizes emergence as 'the view that new and unpredictable phenomena are naturally produced by interactions in nature'. ${ }^{16}$ But is emergence an intelligible notion? On the face of it, the 'experiential' and the 'non-experiential' are utterly different categories of being: how could the purely physical, in the sense of the non-experiential, bring the experiential into existence? This does look like a miraculous feat - a kind of unfathomable creatio ex nihilo. As John Locke forcefully makes the point (although in a different argumentative setting): 'it is as impossible that incogitative matter should produce a cogitative being as that nothing, or the negation of all being, should produce a positive being or matter' ${ }^{17}$

This is the whole point on which the panpsychist rests his case. If the notion of brute emergence is rejected, then one will be brought back to the original contradiction and will have to reconsider either $[\mathrm{RP}]$ or $[\mathrm{NE}]$. One way to abandon [RP] would be to deny the reality of mental phenomena and embrace eliminative materialism. But the very existence of experiences does seem difficult to deny what is more real than the pains I feel when hitting my foot against the table? Nor can it be that they simply appear to be, but are really not: since merely to appear is already to be a part of reality. (If there is a theory that has a fair claim to be regarded as an historical anomaly, isn't this eliminative materialism?)

Alternatively, one might hold that mental phenomena are real while at the same time reject the notion that they are physical. But this would yield a form of supernaturalism and a bifurcation of

16 P. Clayton, Mind and Emergence: From Quantum to Consciousness (Oxford: Oxford University Press, 2004), vi; my emphasis.

17 An Essay Concerning Human Understanding, abridged and edited by John W. Yolton (London: Dent, 1994), IV. X. 11. 


\section{Pierfrancesco Basile}

reality into a material and a mental world. This is unsatisfactory, because the mental is just as natural as the material. Moreover, this solution reopens the vexed question: how could these two worlds intermingle and constitute the single unified universe in which we live? (If there is anything uncontroversial in the philosophy of mind, this is the notion that an understanding of mind's place in nature requires a monistic ontology, that is, one that recognizes only a single kind of basic stuff.)

It is tempting, at this point - the temptation is a strong one, and should be appreciated as such - to succumb to the siren song and to take the radical step of dropping $[\mathrm{NE}]$ out of board:

$[\neg \mathrm{NE}]$ physical stuff is, in itself, in its fundamental nature, NOT something wholly and utterly non-experiential.

This is tantamount to accepting some form of panpsychism. Isn't there any way to resist this conclusion? I admit that the notion of radical emergence is a difficult one. Strawson observes that, if brute emergence were possible, then we couldn't rule out other kinds of miraculous transitions such as the emergence of concrete phenomena from abstract ones. ${ }^{18} \mathrm{I}$ do not know how to prove that miracles do not occur; to admit that they do, however, is to give up on the attempt to understand consciousness' place in nature.

At this juncture, the following objection is likely to arise: 'Sooner or later, science will explain the emergence of the experiential out of the non-experiential: why, then, not suspend judgment and see what science will bring?' 19 This would be to miss the force of the panpsychist's case. We do not need to wait for science to dispel the riddle. The panpsychist does not claim that we do not know at present how to explain brute emergence; rather, the claim is that we already know that such a radical form of emergence is impossible - or, alternatively, that if brute emergence is real, then it is not something we can possibly understand.

Note that this is not to deny that science might one day explain consciousness' place in nature. If it will, however, this will be at the price of abandoning the notion of insentient matter and the conception of emergence that goes with it. To see this is to recognize that the difficulty is not empirical, but conceptual - the gap between the

18 Ibid., 19; for a similar point, see T. Nagel, 'Panpsychism' in Mortal Questions (Cambridge: Cambridge University Press, 1979), 194.

19 See P. Simons, 'The Seeds of Experience' in A. Freeman (ed.), Consciousness and its Place in Nature, op. cit., 148-49, for an objection along these lines. 
experiential and the non-experiential is a logical one: mere acquisition of novel empirical data would not help unless one reframes the concepts that are used to interpret those data. Otherwise put, it is our current concept of matter as that which is wholly and utterly non-experiential which makes it impossible to understand how mind, the experiential, could emerge from it. Surely, the request that we revise our ordinary conception of matter is a radical one, but it is much less drastic than eliminative materialism or Colin McGinn's skeptical suggestion that there is something about our cognitive endowments that makes it impossible in principle to solve the mind-body problem. ${ }^{20}$

Thus, what seems worthy of consideration at this point is whether there is a way of avoiding panpsychism while still rejecting the notion of a brute emergence of the experiential from the non-experiential. Neutral monism might seem to offer a way of escape. Why not argue that reality's basic stuff is neither mental nor physical, and yet it is the ground out of which both experiential and non-experiential properties originate? On closer examination, one easily sees why this solution wouldn't do. If one rejects emergence on the ground of the heterogeneity problem, then one is inevitably committed to saying that mental properties cannot originate from a wholly non-mental source. The neutral substratum will have to possess, if not fullblown mental properties, at least some proto-experiential features; again, this is tantamount to admitting that some form of panpsychism must be true - that the seeds of experience lie deep in the ultimate nature of things.

Nevertheless, the attempt to avoid the panpsychist option by adopting neutral monism is not wholly misguided. The intuition that animates that proposal is that, at an ultimate level of explanation, reality might not be adequately described in terms of the twin notions of 'experiential' ('mental') and 'non-experiential' ('physical'). Perhaps one does not really have to choose between [NE] and [RP]? They could both be false in that they are an inadequate way to set up the stage in the first place.

This seems to be the solution recently favored by Colin McGinn: 'The only way out of this' - he says - 'is to hold out the hope of a third level of description... Brains have properties beyond those of

20 As he has it, 'we are cut off by our very cognitive constitution from achieving a conception of that natural property of the brain (or of consciousness) that accounts for the psychophysical link...the felt mystery comes from our own cognitive limitations, not from any objective eeriness in the world'. C. McGinn, 'Can we solve the mind-body problem?', Mind 98 (1989), 359. 


\section{Pierfrancesco Basile}

experience and those of basic physics and biology. These properties might then mediate between the other two sorts of property, offering some sort of unification of all three levels'. ${ }^{21}$ On this view, one would have to redesign the conceptual landscape in which the whole debate takes place. Significantly, McGinn talks of a mere 'hope' that there might be such a 'third level of description'; the existence of such a level is nothing more than a logical possibility. Thomas Nagel goes a step further along this path, as he speculates that we might find the problem of consciousness intractable simply because we lack the adequate conceptual categories: 'We need entirely new intellectual tools, and it is precisely by reflection on what appears impossible - like the generation of mind out of the recombination of matter - that we will be forced to create such tools'.22

One would not hold to such a hope or aim at such grand conceptual revision, however, unless one had strong reasons for rejecting panpsychism. One main difficulty of the theory will be considered presently. For the time being, it should be emphasized that the argument based upon the heterogeneity problem is a powerful one. 'I suspect', Timothy Sprigge wrote, 'that our reason for believing that something is inherently impossible must always lie in the fact that we find it more and more difficult to conceive of it the more we understand the nature of the elements we are instructed to combine... That is, the nearer we approach intuitive fulfillment of the meaning of the expression said to express it the more we feel baffled'. ${ }^{23}$ On the face of it, brute emergence looks like magic isn't it so? 'The burden of proof lies on the emergentist here.

\section{Mental Composition}

Searle raises a serious question when he says that panpsychism can't 'cope with the problem of the unity of consciousness'. On the panpsychist view, he asks, how do the parts of a sentient whole 'relate to the consciousness of the whole'? For the sake of illustration, let's assume that the human brain (instead of Chalmers' thermostat) is composed of parts that are either sentient or wholly experiential in

21 C. McGinn, 'Hard Questions. Comments on Galen Strawson' in A. Freeman (ed.), Consciousness and its Place in Nature, op. cit., 98.

22 T. Nagel, The View from Nowhere (Oxford: Oxford University Press, 1986), 52.

${ }^{23}$ T. L. S. Sprigge, The Vindication of Absolute Idealism (Edinburgh: Edinburgh University Press, 1983), 128. 
nature. Searle's question now becomes: how do the lesser consciousnesses entering in the constitution of the brain coalesce so as to form the unified consciousness of a human being?

This well-known difficulty was raised by James in his Principles of Psychology. In that book, he compared the experiences in the neurons with the thoughts of several persons in a row:

Take a sentence of a dozen words, and take twelve men and tell to each one word. Then stand the men in a row or jam them in a bunch, and let each think of his word as intently as he will; nowhere there will be a consciousness of the whole sentence. ${ }^{24}$

More recently, Philip Goff has made the example of a big pain composed of several little pains, as it were, by way of addition:

Consider a physical ultimate that feels slightly pained, call it LITTLE PAIN 1. Consider then such slightly pained ultimates, LITTLE PAIN 1, LITTLE PAIN 2, etc., coming together to constitute a severely pained macroscopic thing, call it BIG PAIN. The pained-ness of each of the ultimates comes together to constitute the pained-ness of BIG PAIN: an entity that feels ten times the pain of each LITTLE PAIN. The severe painedness of BIG PAIN is wholly constituted by the slight painedness of all the LITTLE PAINS. ${ }^{25}$

Clearly, a collection of thoughts about single words does not amount to a single thought about a whole sentence; by the same token, an assemblage of little pains is not the same as a big pain, whose qualitative feel differs from that of any of its constituents or of all of them collectively. This is uncontroversial; equally uncontroversial, the transition from the experiences in the neurons to the human experience cannot be accepted as a brute contingency, but stands itself in need of explanation. This is no trivial point. Should this transition prove to be inexplicable, one will have to conclude that panpsychism is in no better position than any of the alternatives examined in the previous section, as it would face its own version of the problem of emergence.

But do we know that such a transition - from the low-level experiences to the higher human experience - cannot possibly take place? On the basis of what has been said so far, there is no reason to construe the composition problem as a reductio ad absurdum of the doctrine of

P. Goff, 'Experiences Don't Sum' in A. Freeman (ed.), Consciousness and its Place in Nature, op. cit., 57. 


\section{Pierfrancesco Basile}

mental combination and, by implication, of panpsychism. Specifically, the panpsychist need not be committed to the view that the lesser selves should bring about a larger consciousness in the same way in which, say, mosaic pieces come together to form the larger picture. Their mode of combination must be of an altogether different type. Surely, there is nothing in either Searle's or Goff's passages to warrant their contention that panpsychism is incoherent.

Quite recently, Goff himself has recognized that, as stated above, the criticism does not suffice to show that mental composition is impossible in principle: 'Contrary to views I have expressed in earlier work' - he now writes - 'I believe that the panpsychist can make good sense of subjects of experience summing, and hence can get round the combination problem' ${ }^{26}$ As against this, I do think that the notion of mental composition poses a very hard challenge for panpsychism. To see why this is so, however, an attempt must be made to formulate the problem in more precise terms.

\section{Why is There a Problem?}

What assumptions about the nature of experience generate the problem? Strangely enough, this question is rarely asked; it just seems to be taken for granted that we have an adequate grasp of the difficulty at issue. But consider the two passages quoted above. James' question is about intentionality - how could mental events, each of which has a different intentional object (a single word), generate a mental event with a new intentional object (a whole sentence)? Goff's is about qualia - how could mental events, each of which has its own 'what-is-it-like-feeling', generate a mental event that has its own distinct phenomenology (the feel of a big pain as opposed to that of a little one)? Without wishing to adjudicate the question as to the nature of the relationship between the two alleged 'marks' of the mental - 'intentionality' and 'subjectivity' - , it should be admitted that it is not immediately clear that these questions are the very same one or that the solution to the one will entail the solution to the other.

Let's here consider the problem in terms of qualia. After all, it is the subjective, qualitative dimension of conscious experience that

26 P. Goff, 'Can the panpsychist get around the combination problem?' in D. Skrbina (ed.), Mind that Abides: Panpsychism in the new millennium (Amsterdam-Philadelphia: John Benjamins Publishing Company, 2009), 133. 
has led contemporary philosophers to reconsider the heterogeneity problem, thus providing the motivation for panpsychism in the first place. ${ }^{27}$ Once more, it is to James that we will turn for advice. In his later work, A Pluralistic Universe, he provides a most interesting evaluation of panpsychism. This is developed in the context of a discussion of the philosophies of Gustav Fechner and Josiah Royce. As James himself points out, however, what he says possesses a broader philosophical significance and a general critique of panpsychism can be extrapolated. ${ }^{28}$

Drawing freely from James' exposition, the problem might be construed as depending upon a few assumptions as to the nature of our experience:

PHENOMENAL ESSENTIALISM - this is the view that, for an experience, to be is to feel a certain way. In the case of a pain, it seems pointless to draw a distinction between what the pain is in itself and the way it feels; the former - what the pain is 'in itself' is wholly exhausted by the latter - its qualitative, felt dimension. As James forcefully puts it, in the case of experience, 'appearance' and 'reality' are one and the same. ${ }^{29}$

Besides the idea that an experience is nothing over and above the manner of its appearance - the idea that 'a mental fact' is 'just what it appears to be' 30 - there is another assumption that needs to be taken into account. This is one James would seem to endorse in the Principles of Psychology:

PHENOMENAL HOLISM - this is the view that, within a person's total psychical whole, the nature of a single identifiable experience ('single', in the sense that it can be counted as 'one') is essentially determined by the other experiences occurring alongside it - synchronically - within the whole.

This principle involves a rejection of the traditional atomistic view of the mind, one typically exemplified by Hume's notion of a perception as a self-subsistent, substance-like entity that could, as a matter of

Another limitation, already implicit in what has been said so far, is that the problem will be discussed with respect to consciousness' synchronic unity, as opposed to its unity over time.

28 W. James, A Pluralistic Universe: Hibbert Lectures at Manchester College on the Present Situation in Philosophy (London-Bombay-Calcutta: Longmans, Green, and Co., 1909), 192.
29 Ibid., 198-9.
30 Ibid., 200. 


\section{Pierfrancesco Basile}

sheer logical possibility, exist outside of the larger field of consciousness in which it actually occurs. ${ }^{31}$ According to James, a person's psychical field at any one moment constitutes a non-decomposable unity; its several contents are to be viewed as 'aspects' mutually determining and interpenetrating each other rather than as 'parts' in any literal sense of this word. James' commitment to this view is implicit in his remark that 'each thought [a total moment of experience] is a fresh organic unity'. ${ }^{32}$ The denomination 'organic unity' commonly refers to a totality whose parts are internally related, such that the nature of each essentially depends upon that of all others.

For the sake of illustration, imagine what it would be like to drink a cup of coffee in Naples as opposed to drinking it in Edinburgh: isn't it plausible to think that the different atmospheres of the two cities (the characteristically different colours, sounds, flavours etc. one experiences there) would make a difference to the coffee's taste? The two tastes, as they occur in the total states 'Coffee-in-Naples' and 'Coffee-in-Edinburgh', would seem to be different - qualitatively, and therefore also numerically - experiential occurrences.

Let's now consider the relation between the mind and the brain. It is unlikely that the panpsychist would want to reinstall the notion of the soul as an entity separate from the brain and causally interacting with it. Most likely, he is bound to speculate that the 'larger mind' of a human being is constituted by the 'lesser minds' of the neurons. This would seem to require that an experience belonging to (or even wholly constituting) a neuron's lesser mind be also felt by the larger subject which is the human mind. Such a view would involve what James refers to as 'the assumption that states of consciousness... can separate and combine themselves freely, and keep their own identity unchanged while forming parts of simultaneous fields of experience of wider scope'. ${ }^{33}$ This underlying assumption can be recast as follows:

THE SHARING PRINCIPLE - this is the view that an experience can simultaneously occur within two distinct psychical wholes - i.e. the very same experience can be felt by two different feelers, in this case, by the 'lesser mind' of the neuron and the 'larger mind' of the human being.

31 D. Hume, A Treatise of Human Nature, edited by D. F. Norton and M. J. Norton (Oxford: Oxford University Press, 2000), 137-8.

32 W. James, The Principles of Psychology, op. cit., 279n; see also 145 and 241 .

33 W. James, A Pluralistic Universe, op. cit., 181. 
Once these notions are accepted, it becomes clear that the notion of mental combination involves a contradiction. If mental combination is to be possible, an experience must be felt by two different subjects while remaining numerically self-identical. But if the being of an experience is wholly exhausted by the way it feels, then an experience cannot be numerically the same while being felt by two different feelers. So, it would seem, mental composition is an impossible conception.

In order to see which options are actually open to a philosopher faced which this difficulty, it might be helpful to derive the contradiction in a more formal way. If mental combination is possible, then the same one experience, $E$, must be felt by the human mind $M$ as well as by the neuronal mind $N$. At the same time, according to phenomenal essentialism, an experience is nothing but the way it feels; hence, the following two theses must both be true:

[1] $E=E$-as-felt-within- $N$

[2] $E=E$-as-felt-within- $M$

But how can this be? Since $N$ and $M$ are per hypothesis different, and $M$ is surely going to have a richer content than $N$, this implies:

[3] $E$-as-felt-within- $N \neq E$-as-felt-within- $M$

By substitution of [1] and [2] in [3], one gets:

[4] $E \neq E$

But this is a clear violation of the logic of identity! In order for mental composition to be possible, an experience would then have to possess two natures - it would have to be itself and yet another thing. Surprisingly enough, James did not believe that the discovery of this contradiction amounted to a refutation of panpsychism; influenced by the then emerging philosophy of Henri Bergson, he chose to reject the logic of identity as adequate to an understanding of experience. ${ }^{34}$ This is not an option to be ridiculed, but it is not to be welcomed either; ultimately, what one aims at in philosophy is rational, conceptual understanding.

Thus, it would seem that the panpsychist will have to renounce one of the principles involved in the derivation. Which one should he choose? The most likely candidate is the idea that experiences can be shared. This seems reasonable enough; after all, the privacy of our experience $-i . e$. the fact that each of us is the only individual who can possibly know what his or her experiences feel like - is a

Ibid., 212 and 214. 


\section{Pierfrancesco Basile}

commonplace of every-day life. ${ }^{35}$ Note that the point is not the epistemological one that we cannot know what another person's experience feels like, but ontological: experiences are such that they cannot be felt by more than one subject. And yet, to abandon the notion of a 'sharing' of experiences comes at a price; the panpsychist would seem to require this notion in order to make sense of mental composition and thereby account for the relation between the mind and the brain.

One final remark: it could be objected that the above argument does not show that there is any problem in principle with sharing across numerically distinct subjects if no other experiences were going on. This is true but, I think, irrelevant to the present case; it is only reasonable to assume that the human mind is a richer whole of experience than the (alleged) mind of a single neuron. Still, the question is important, as it suggests that there might be stronger ways of arguing for the privacy of our experiences - that is, without having to assume that there are differences in the subjects' other experienced contents and thereby without an appeal to the principle of phenomenal holism. As a matter of fact, a closer look at the principle reveals that it is not as evident as it might initially appear. James says little to support phenomenal holism, and while there are very obvious illustrations of it (a glass of wine has a better taste when enjoyed in a pleasant surrounding), the principle does seem somewhat implausible in other circumstances. Would the red of the book's cover in front of me have a different feel if I were not hearing music at this moment? It is difficult to tell, but there is room for scepticism here. ${ }^{36}$

\section{Conclusion}

Where does this leave us? Nagel has remarked that Cartesian dualism 'is usually adopted on the ground that it must be true, and often

35 Using Samuel Alexander's little known but very apt terminology, 'knowing' our experiences means here apprehending them by way of 'enjoyment', simply by living through them as it were, rather than knowing them as one knows an object of contemplation. See his Space, Time and Deity: The Gifford Lectures at Glasgow, 1916-1918, Vol. I (London: MacMillan \& Co., 1924), xiv.

36 For a critical assessment of phenomenal holism, see B. Dainton, Stream of Consciousness. Unity and Continuity in Conscious Experience (London and New York: Routledge, 2000), 181-213 and see his paper in this volume. 
rejected on the ground that it can't be true' ${ }^{37}$ The same could now be said of panpsychism, as the argument based upon the heterogeneity problem is counterbalanced by the problem of mental composition. Nagel's own conclusion is that 'panpsychism should be added to the list of... hopelessly unacceptable solutions to the mind-body problem', ${ }^{38}$ but it would be premature to reject a doctrine supported by such a strong argument; rather, the hope is that what has been said might help to circumscribe the theory's 'logical space' - the legitimate area of argumentative manoeuvre for any attempt to make sense of mental composition.

If the above considerations are sound, then there are at least two requirements that any viable formulation of the theory must be capable of satisfying:

[A] The panpsychist should reject the idea that larger experiential wholes are brought into existence by way of simple addition of lesser experiential realities; mental items must combine in a way that is categorically different from the way in which stones and bricks combine to form a house, or several pieces of a puzzle to yield the whole picture. These simply aren't the right combinatory models. (This might seem an obvious point to make; as it has been shown, however, it is also one that is easily overlooked.)

[B] The panpsychist should fully acknowledge that experiences are private. This means that the notion of mental composition should not be construed as involving the idea that experiences can be literally 'shared' - 'owned' as it were by two different subjects. (To put it in idealistic terms: if the being of an experience is wholly exhausted by its sentiri, no experience can preserve its identity while felt by different feelers.)

Trivial as they might appear, these are severe constraints. Is there any known version of panpsychism that satisfies these demands? The only candidate that comes to mind is Leibniz's theory of causally independent monads. [A] The monads constituting our body do not sum up by way of addition to give rise to the human mind, which is a distinct, separate individual. And while he contends that our individual minds comprise an infinite number of unconscious petites perceptions, ${ }^{39}$

37 T. Nagel, The View from Nowhere, op. cit., 29.

38 T. Nagel, 'Panpsychism', op. cit., 193.

39 G. W. Leibniz, 'Introduction to New Essays on the Human Understanding', in The Monadology and Other Philosophical Writings, edited and translated by R. Latta (Oxford: Clarendon Press, 1898), 370. 


\section{Pierfrancesco Basile}

these are not to be thought of literally as 'parts' of our entire psychical whole; on the contrary, our minds are Leibniz's paradigmatic examples of genuine units or indivisible substances. [B] Furthermore, since monads are 'windowless', they do not literally share their contents with any other monad; although all monads perceive the same universe, each enjoys its own private mental world.

But wouldn't a recurrence to a Leibnizian metaphysics of windowless monads be a price too high even for a panpsychist to pay? Fortunately, this question can be postponed. In view of the strength of the panpsychist's case, what is needed is more work on the composition problem. In the passage quoted at the very beginning of this paper, Searle says that he cannot see 'any way that it [panpsychism] can cope with the problem of the unity of consciousness'. Undeniably, the problem is a difficult one; I have argued in this paper that - perhaps - there is a way. We lack at present a firm understanding of phenomenal parts and wholes, but-pace Searle (and Goff) - it is equally true that we do not know that mental composition is impossible in principle. Compared with the ferocious intensity with which other questions have been debated - such as, for example, mental causation or supervenience - this is an undeveloped area of research in contemporary philosophy of mind. ${ }^{40}$

University of Bern, Switzerland

40 I would like to thank Leemon McHenry, Pauline Phemister and Galen Strawson for helpful comments on an earlier version of this paper. 